\title{
The roles of surgery, stereotactic radiation, and ablation for treatment of pulmonary metastases
}

\author{
Mara B. Antonoff, MD, ${ }^{\mathrm{a}}$ Constantinos T. Sofocleous, MD, PhD, ${ }^{\mathrm{b}}$ Matthew R. Callstrom, MD, $\mathrm{PhD},{ }^{\mathrm{c}}$ and \\ Quynh-Nhu Nguyen, MD $^{\mathrm{d}}$
}

For patients with extrapulmonary primary malignancies, the lung is the most frequent site of metastatic spread. ${ }^{1}$ Pulmonary metastatic disease is experienced commonly in colorectal cancer (CRC), sarcomas, melanoma, head and neck cancers, breast cancer, and tumors of the urinary tract, with numerous other malignancies known to additionally spread to the lungs. ${ }^{2,3}$ Historically, systemic therapy has been considered standard of care for stage IV cancer, given the systemic nature of the disease; however, options for local therapy of metastatic pulmonary nodules are expanding, with substantial evidence for efficacy in terms of optimal local control for prolonging life, delaying recurrence, and enabling patients to experience freedom from chemotherapy. ${ }^{4}$

With regard to the benefits of local therapy for pulmonary metastatic disease, the existing literature can be challenging to interpret, given the broad heterogeneity of the populations included, spanning numerous histologies, extents of disease burden, and types of treatment. ${ }^{5}$ Even within focused series, there can be vast differences among patient outcomes related to the type of surgical resection or modality of ablative therapy. Although it would be inappropriate to offer local therapy for all patients with pulmonary metastatic disease, it is well established that there are substantial benefits to selected populations of patients. In addressing the role of local therapies for pulmonary metastatic disease, there are a number of highly relevant questions that must be considered: (1) Is this disease biology appropriate for local therapy? (2) Is this patient a good candidate for local therapy? (3) What is the optimal timing for providing local therapy to this patient? (4) What is the most suitable local modality for treating this patient?

Pertaining to disease biology, it is known that certain tumor histologies have a tendency to lead to prolonged disease-free intervals (DFIs) after local therapy, whereas

\footnotetext{
From the a Departments of Thoracic and Cardiovascular Surgery, and ${ }^{\mathrm{d}}$ Thoracic Radiation Oncology, University of Texas MD Anderson Cancer Center, Houston,

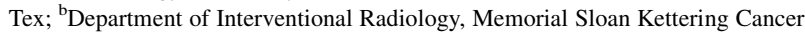
Center, New York, NY; and ${ }^{\mathrm{c}}$ Department of Radiology, Mayo Clinic, Rochester, Minn.

Received for publication Aug 31, 2020; revisions received Nov 16, 2020; accepted for publication Jan 2, 2021; available ahead of print March 6, 2021.

Address for reprints: Mara B. Antonoff, MD, Thoracic and Cardiovascular Surgery, UT MD Anderson Cancer Center, 1400 Pressler St, Unit 1489, Houston, TX 77030 (E-mail: mbantonoff@mdanderson.org).

J Thorac Cardiovasc Surg 2022;163:495-502

$0022-5223 / \$ 36.00$

Copyright (c) 2021 by The American Association for Thoracic Surgery

https://doi.org/10.1016/j.jtcvs.2021.01.143
}

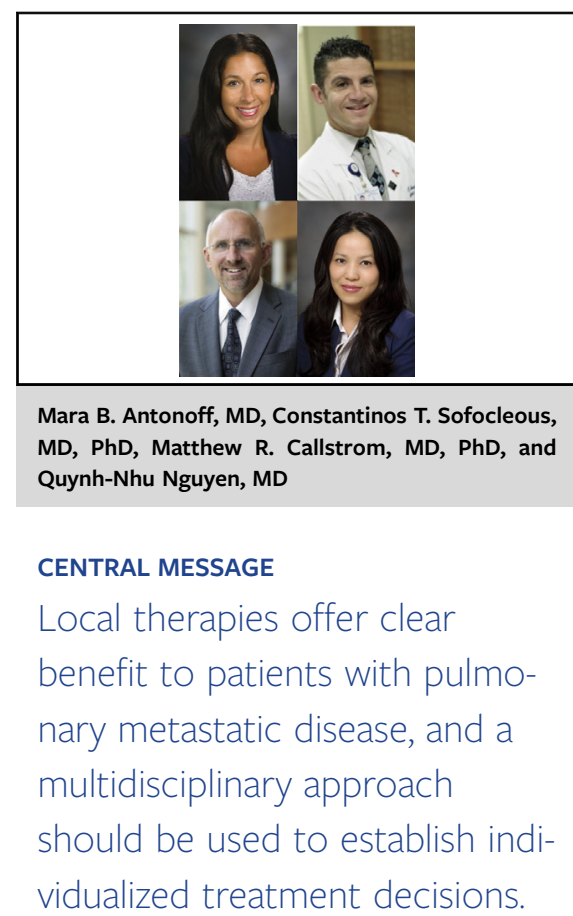

See Commentaries on pages 503 and 510.

others tend to recur quickly. In general, the demonstration of disease stability and absence of extrathoracic metastases are well accepted as factors that are associated with better outcomes after local therapy. ${ }^{6}$ Furthermore, the ability to locally address all sites of disease is a particularly important consideration with regard to higher-risk interventions. ${ }^{1}$ Finally, it is relevant to consider that some tumors have alternative management strategies that are well tolerated by patients, such as those who can be managed by oral hormonal agents, whereas other diseases may be treatable only by highly toxic chemotherapeutic agents or may not even treatable with systemic drugs at all. All of these elements of disease biology are pertinent to the discussion of offering local therapy.

As with therapeutic interventions for any medical condition, one must consider not only the best way to treat the disease but also whether the patient is an appropriate candidate for the treatment. For local therapy to the lung, patient comorbidities are particularly germane, as this may often weigh heavily in the decision as to which form of local therapy is offered. For patients to be surgical candidates, one must consider pulmonary reserve, frailty, and general 
ability to tolerate both a general anesthetic and the surgical recovery. For less-invasive ablative therapies, pulmonary function remains relevant, but with less stringent limitations than for surgery. Beyond comorbidities, other patientrelated factors include social support, compliance with medical advice, and emotional well-being.

Optimal timing and sequencing of specific local intervention are imperative to ensure successful patient outcomes. In some circumstances, patients may benefit from upfront systemic treatment to reduce tumor volume, which may increase efficacy of subsequent radiation or ablative therapies and/or reduce the amount of parenchyma required for resection. However, if tumors are particularly responsive to systemic therapy, small subcentimeter nodules may be difficult to localize, both radiographically and intraoperatively. Thus, the interplay of systemic therapy with local therapies is an important component of the multidisciplinary discussion. While limited studies have delved into this relationship between local and systemic therapies, it is the subject of a current ongoing trial in lung-limited metastatic CRC. ${ }^{7}$

There are a variety of modalities available for treatment of pulmonary metastases and numerous considerations guiding the applicability of each modality. Ultimately, for some patients, there may be an obvious best approach, whereas for others, there may be multiple reasonable strategies. Still yet for others, complete local control of pulmonary metastases may be best achieved with a hybrid approach. From here, we aim to delve into the realms of surgery, radiation, and transthoracic ablative therapies, identifying the best uses for each, with the overarching goal of highlighting the rationale for offering local therapy to patients with pulmonary metastatic disease.

\section{ROLE OF SURGERY FOR PULMONARY METASTASES}

While novel approaches to local therapy have emerged in recent years, surgery has been the mainstay of local therapy for pulmonary metastatic disease. The predominance of literature supporting this approach has been composed of retrospective reviews. Although variability in patient populations and treatments has rendered a range of outcomes, in general, there is clear demonstration of improvement in prognosis for appropriately selected surgical patients. ${ }^{1}$

The greatest volume of data related to local therapy for pulmonary metastatic disease - and particularly related to surgical resection-addresses CRC, as this is the most common malignancy to spread to the lungs, with up to $18 \%$ of patients developing pulmonary metastatic disease. ${ }^{8}$ There is an abundance of single-institution retrospective reviews evaluating the benefits of surgery in this population, which have been summarized through several meta-analyses and systematic reviews. A meta-analysis published by Gonzalez and colleagues ${ }^{9}$ in 2013, reporting on nearly 3000 patients treated with metastasectomy, showed 5-year survival after resection of up to $68 \%$. In this study, median DFI ranged 19-39 months, with longer DFI being associated with greater survival (hazard ratio [HR] for shorter DFI, 1.59). Survival was also better among patients without intrathoracic nodal disease or multiple pulmonary nodules (HR for nodal involvement, 1.65; HR for $>1$ nodule, 2.04). ${ }^{9}$ In 2016, Lumachi and colleagues ${ }^{8}$ analyzed outcomes from 15 retrospective studies, describing a median 5-year survival of $45 \%$ after surgery, with some patient cohorts achieving 5 -year survival as high as $72 \%$. This study, as well as a subsequent meta-analysis published in 2018, corroborated the findings that patients with the best prognosis following surgical resection were those with longer DFI, fewer pulmonary nodules, and absence of intrathoracic nodal disease. ${ }^{8,10}$ Mutational status has also been shown to prognosticate outcome after resection of colorectal pulmonary metastases, with patients harboring mutant APC showing prolonged survival, whereas KRAS mutations have been associated with poorer outcomes after resection. ${ }^{8,11}$ An additional prognostic factor for survival after pulmonary metastasectomy relates to the location of the primary CRC; patients with rectal tumors display shorter disease-free survival after pulmonary metastasectomy than those with colon tumors, ${ }^{12}$ while patients whose initial tumors arose in the left-sided segments of colon (vs rightsided) tend to demonstrate the greatest survival benefit after lung resection. ${ }^{13}$

Surgery has also been shown to extend survival for patients with metastatic sarcoma. A review by Marulli and colleagues ${ }^{14}$ demonstrated 5 -year survival ranging from $15 \%-51 \%$, with tumor histology being particularly important to likelihood of survival after resection, in that patients with osteosarcoma fared substantially better than those with soft-tissue sarcoma. ${ }^{14}$ Among soft-tissue sarcomas, resection of leiomyosarcoma metastases appears to have the greatest impact in prolonging survival. ${ }^{14,15}$ Similar to the data for colorectal metastases, patients with sarcomatous pulmonary metastases appear to achieve the best survival after pulmonary resection when they have fewer nodules, longer DFIs, and negative margins at the time of surgery. ${ }^{14,15}$

Surgical therapy has further been found to be beneficial for pulmonary metastases from renal cell cancer as well as melanoma. For renal cell cancer, pulmonary metastasectomy has been shown to portend a 5-year survival in the range of $36 \%-53 \%{ }^{16,17}$ Similar benefit has been demonstrated in melanoma. ${ }^{16,18}$ As has been seen for CRC and sarcoma, patients with pulmonary metastatic disease from renal cell cancer and melanoma also appear to have greater benefit from metastasectomy when fewer lesions are present, DFI is longer, intrathoracic nodes are uninvolved, and surgical resection is complete. ${ }^{4,16,17}$ Germ cell tumors (GCTs) represent another tumor for which pulmonary metastasectomy may be of benefit, and although these 
malignancies are relatively rare among the general population, it is recognized that more than $10 \%$ of patients with this diagnosis develop pulmonary metastatic disease. ${ }^{19}$ Pulmonary resection for GCT has been used for approximately 40 years with excellent retrospective results. Timing for lung surgery is thought to be particularly important in this patient population, just as in management of the primary GCT, with emphasis placed on performing metastasectomy after completion of cisplatin-based chemotherapy and normalization of serum tumor markers. ${ }^{20}$

With regard to surgical technique, it is commonly accepted that, for metastasectomy, parenchymal-sparing strategies should be emphasized, which contrasts somewhat to the management of primary lung cancer. Rationale for such an approach is based on the frequent need for resection of multiple nodules, the potential need for future resections and/or ablative therapy, the lack of data demonstrating benefit for more extensive anatomic resections, and the expectation of less postoperative morbidity. ${ }^{1,21,22}$ Thus, the most frequent approach is a stapled wedge resection, whereas lobectomies may be used for larger tumors, central tumors, or the presence of multiple metastases within a given lobe. ${ }^{21}$ Of course, it should be noted that surgical technique is key, with high risk of recurrence with inadequate margins. ${ }^{23}$ While circumstances for more extensive resection than wedge or lobectomy are exceedingly uncommon, highly selected patients may be considered for pneumonectomy for solitary, central tumors after a prolonged DFI demonstrating disease stability and absence of any disease elsewhere. ${ }^{24,25}$

The optimal operative approach for pulmonary metastasectomy has been highly debated. Studies evaluating intraoperative efficacy of thoracoscopy versus thoracotomy have demonstrated superior ability to find nodules anticipated by imaging upon thoracotomy and manual palpation, as well as greater likelihood of finding and removing additional nodules not detected on imaging. ${ }^{26,27}$ Regardless, multiple investigators have failed to show differences in 5-year survival based on surgical approach. ${ }^{16,28}$ Further complicating the issue, it should be recognized that such studies may fail to show survival differences based on operative approach because of the inclusion of such widely disparate disease biology within the patient cohorts. A recent consensus document emphasizes minimally invasive approaches where feasible. ${ }^{25} \mathrm{Ul}-$ timately, as it has been demonstrated that the perioperative benefits of thoracoscopy compared with thoracotomy are nearly equalized when enhanced recovery pathways are applied, ${ }^{29}$ the specific operative approach should be left to the operating surgeon, based on the number of nodules, their exact anatomic locations, and other patient-specific factors.

At the time of surgery for pulmonary metastatic disease, there has not been a clear survival benefit demonstrated by the performance of lymphadenectomy, ${ }^{30}$ although, again, this may be consequent to inclusion of heterogeneous patient populations. It is clear that those patients who have intrathoracic nodal disease tend to have worse survival after pulmonary metastasectomy, ${ }^{31}$ which may both give pause to the notion of operating in the setting of known nodal disease and further emphasize the possible prognostic utility of nodal sampling during planned operations. ${ }^{1,25}$

Prospective studies evaluating the role of pulmonary metastasectomy have been lacking until recently. The Pulmonary Metastasectomy versus Continued Active Monitoring in Colorectal Cancer trial aimed to evaluate the additive benefit of surgery compared with active surveillance, but closed in December 2016 because of poor recruitment. ${ }^{32}$ Subsequent analyses of the dataset demonstrated that patients in the control (nonoperative) group had better survival than had been assumed. ${ }^{33}$ However, this study was limited by several factors, including the fact that the majority of patients enrolled displayed highly favorable characteristics in terms of DFI and number of nodules, and that systemic agents were used by about one-half of the patients in both groups, yet were not standardized. Thus, we uphold that one of the goals and benefits of local therapy (including surgery, radiation, or ablative therapy) is to provide patients with potential freedom from systemic agents. While completed clinical trials are lacking in the area of pulmonary metastasectomy, another multicenter trial is currently underway, under the umbrella of the Thoracic Surgery Oncology Group (TSOG), examining multimodality management of risk-stratified patients with lung-limited metastatic CRC. ${ }^{7,34}$ The primary goals of this study (TSOG 103) are to evaluate the additive benefit of chemotherapy on recurrence-free survival in low-risk patients undergoing metastasectomy, as well as to assess the role of surgery in prolonging overall survival among high-risk patients undergoing systemic therapy.

While we currently use a variety of patient- and diseaserelated factors to determine the best modality of treatment, management algorithms in the future may depend on genomic and biomarker status. For example, as noted earlier with CRC, the mutational status may affect the likelihood of prolonged survival after metastasectomy, and, thus, those with APC mutations may be best advised to undergo resection. ${ }^{11}$ Moreover, our fund of knowledge regarding genetic and tumor markers in pulmonary metastatic disease continues to grow, enabling us to further optimize our recommendations for individual patients in the future. In the TSOG 103 trial, while primary endpoints evaluate the interplay of various treatment modalities on survival outcomes, additional exploratory objectives involve the evaluation of changes in circulating tumor DNA after surgical resection or chemotherapy. ${ }^{7,34}$ It is hoped that such information can set the groundwork for future trials such that biomarker status may be used to guide timing 
and choice of treatment modality for patients with pulmonary metastatic disease.

\section{ROLE OF STEREOTACTIC ABLATIVE BODY RADIATION FOR PULMONARY METASTASES}

Although surgery has traditionally been the primary local modality for treating metastases, less invasive alternatives such as stereotactic ablative body radiation (SABR) and thermal ablation are becoming more widely accepted, either as primary therapy for select patient cohorts or as consolidative therapy after surgery. ${ }^{35}$ As a convenient, noninvasive, safe alternative to surgery, SABR allows high ablative radiation doses to be delivered by using highly conformal techniques that avoid exposure of nearby critical normal tissues and can provide excellent local control with minimal toxicity. In this era of significant improvement in systemic therapy extending survival for patients with multiple metastases, there are continual studies demonstrating the role for SABR for a number of different primary histologies. For example, one meta-analysis of 15 studies showed that SABR for 686 pulmonary metastases from CRC led to local control rates of $81 \%$ at 1 year, $66 \%$ at 2 years, and $60 \%$ at 3 years. These local control rates were worse for pulmonary metastases from CRC primaries than for metastases from non-CRC primaries (perhaps because CRC metastases require higher biologically effective doses), but overall survival was higher. ${ }^{36}$ However, another report of SABR for 134 pulmonary metastases from cancer of various types (including CRC), with prescribed doses of 30-60 Gy delivered in 1-5 fractions, showed considerably higher local control rates: At a median follow-up time of 17 months, local control rates were $97.6 \%$ at 1 year, $90.6 \%$ at 2 years, and $87 \%$ at 3 years. ${ }^{37}$ The German Working Group on Stereotactic Radiotherapy reported excellent local control and overall survival among a subset of 76 pulmonary metastases from renal cell carcinoma in patients who were not candidates for surgery; SABR, delivered in doses ranging from $24 \mathrm{~Gy}$ in a single fraction to $45 \mathrm{~Gy}$ in 3 fractions, produced local control rates of $98.1 \%$ at 1 year and $91.9 \%$ at 3 years, with corresponding overall survival of $84.3 \%$ and $43.8 \%{ }^{38}$ Another retrospective analysis of 107 pulmonary metastases from head and neck primaries showed that SABR led to excellent rates of local control $(94 \%)$ and locoregional control $(90 \%)$ with an overall survival of $62 \%$ at 2 years. ${ }^{39}$ The 2-year overall survival in that study was higher for patients with oligometastatic versus polymetastatic disease ( $72 \%$ vs $44 \%, P=.008$ ). Further, SABR was reported to be well tolerated, with no reported grade $>3$ toxic events. ${ }^{39}$

Several larger retrospective analyses have also been reported, including one report from MD Anderson of 406 pulmonary metastases from several types of primary tumors treated with SABR to doses of 40-50 Gy in 4 fractions (for peripheral disease) or $70 \mathrm{~Gy}$ in 10 fractions (for central disease).$^{40}$ In that study, SABR for pulmonary metastases from adrenal, colorectal, sarcoma, or pancreatic primaries resulted in higher local failure rates $(4.6 \%)$ compared with metastases from other primaries $(4.6 \%$ vs $1.6 \%$ at 1 year; $12.8 \%$ vs $3.9 \%$ at 2 years). Overall survival also depended on number of pulmonary metastases, being higher for patients with up to 3 pulmonary metastases than for patients with more than $3(74.2 \%$ vs $59.3 \%$ at 2 years; $47.7 \%$ vs $35.1 \%$ at 4 years). This large series of patients with pulmonary metastases from different primary histology experienced excellent local control with SABR and little toxicity. ${ }^{40}$ Another review from the German Working Group considered prognostic factors influencing survival and local control in a multi-institutional database of $700 \mathrm{pa}-$ tients with inoperable disease and pulmonary metastases from a variety of primary types; SABR was delivered to doses of 24-30 Gy, either in single fractions or in 5 to 8 fractions, with biologically effective doses of more than $100 \mathrm{~Gy}$. The overall survival for all patients in that study was $75.1 \%$ at 1 year and $54.4 \%$ at 2 years; local control rates were highest for patients whose primaries were CRC or breast cancer $(90.9 \%$ at 1 year and $81.2 \%$ at 2 years $) .{ }^{41}$

Evidence from phase II trials also suggests that SABR is an attractive alternative to surgery for oligometastatic disease. In the phase II SABR-COMET trial, ${ }^{42}$ patients with 1 to 5 oligometastatic lesions and controlled primary tumors were randomly assigned to standard-of-care palliation or standard-of-care plus SABR to all metastatic lesions. The progression-free survival time after SABR was double that of palliation (12 months vs 6 months, $P=.012){ }^{42}$ Although this study included a heterogeneous patient population, the findings are promising and serve as impetus for further large-scale studies of more focused cohorts. In another single-institution phase II trial, patients with limited metastases from non-small cell lung cancer (NSCLC) were randomized to maintenance chemotherapy or SABR followed by systemic therapy. ${ }^{43}$ Again, SABR led to significantly extended progression-free survival (9.7 months vs 3.5 months, $P=.01$ ), and the type and severity of toxic effects were similar in both arms. ${ }^{43}$ Welsh and colleagues ${ }^{44}$ conducted a phase II trial of 106 patients evaluating the combination of the immunotherapy agent ipilimumab with SABR, at doses of $50 \mathrm{~Gy}$ in 4 fractions or $60 \mathrm{~Gy}$ in 10 fractions to metastatic lesions of the liver and lung. The 1-year, 2-year, and 3-year overall survivals were $76 \%, 73 \%$, and $73 \%$, respectively. There appears to be an abscopal effect when SABR is combined with immunotherapy, as the authors observed a $26 \%$ clinical benefit in nonirradiated tumor with a $31 \%$ response rate in the pulmonary metastases group compared with $14 \%$ response in the liver metastases group $(P=.061) .{ }^{44}$ At this time, several phase III randomized trials are under way to evaluate SABR for patients with oligometastatic disease, including SABR-COMET 3 (1-3 metastases); SABR-COMET 10 (4-10 metastases); CORE (for patients with prostate, breast, 
or NSCLC primaries); and SARON (NSCLC), to help identify which patients will benefit from local consolidation with SABR. Welsh and colleagues ${ }^{44}$ have a number of ongoing trials investigating combined immunotherapy and/or targeted therapy with SABR, lending support for optimal local and systemic responses further improving patient outcomes and survival.

\section{ROLE OF TRANSTHORACIC ABLATION FOR PULMONARY METASTASES}

Beyond surgery and radiotherapy, there are several emerging strategies for percutaneous ablation of pulmonary metastases. For appropriately selected patients, the National Comprehensive Cancer Network guidelines suggest consideration of ablative techniques alone or in conjunction with surgery, provided that all visible disease is eradicated. ${ }^{35}$ Ablation offers the benefit of being able to safely treat metastases while preserving normal pulmonary parenchyma and function. ${ }^{45-47}$ Percutaneous ablation has been shown to be a technically feasible and relatively safe treatment option for patients with new and recurrent pulmonary metastases, with a preponderance of the existing data in the area of colorectal metastases. ${ }^{48-54}$ Generally accepted criteria for percutaneous pulmonary ablation include patients with controlled extrapulmonary disease, fewer than 3 nodules in each hemithorax, and the largest tumor diameter ideally less than $2 \mathrm{~cm}$, surrounded by aerated lung. ${ }^{55-60}$ However, there is no absolute upper limit cutoff in terms of size, recognizing that larger tumors could be considered on a case-by-case basis, dependent on nodule location and ability to create margins. Several factors affecting outcomes after thermal ablation for specifically colorectal pulmonary metastases have been identified. In this patient population, tumor size greater than $2 \mathrm{~cm}$ is associated with poorer overall survival and local tumor control. ${ }^{52,61,62}$ Lower carcinoembryonic antigen level $(<10 \mathrm{ng} / \mathrm{mL})$ has been associated with better survival after ablation. ${ }^{61}$ Among previous investigations, tumor size has remained a fairly consistent limiting factor for the widespread use of ablation, regardless of type of energy used. ${ }^{52}$ Prior authors have shown that the most favorable local tumor control has been due to a small tumor size ${ }^{63}$ and the creation of $\geq 5 \mathrm{~mm}$ minimal ablation margin, which is considered a minimum requirement for pulmonary ablation.${ }^{48,51,61}$ In a review by de Baere and colleagues, ${ }^{48}$ again, it was shown that poorer outcomes from radiofrequency ablation (RFA) were seen with size greater than $2 \mathrm{~cm}$ (HR, 2.10; $P=.0027$ ); not surprisingly, similar to findings from other modalities (such as surgery), greater number of metastases $(\geq 3$ nodules, HR, 1.86, $P=.011)$ and shorter DFI were also associated with worse oncologic outcomes. ${ }^{48}$ Beyond the size of the pulmonary nodule, location is also relevant to the success of percutaneous ablation. As demonstrated by several authors, successful tumor ablation is significantly more frequent for nodules less than $3 \mathrm{~cm}$ that are found within the periphery of the lung. ${ }^{52,64-66}$ Genetic signatures and predictive biomarkers have been associated with post-lung ablation cancer-specific survival. ${ }^{67}$

Early studies reporting on technical feasibility have included mixed patient cohorts of both primary lung cancer and pulmonary metastatic disease. In a retrospective study using RFA to treat patients with primary lung (116 lesions) and pulmonary metastases (73 lesions), reported local control was significantly higher for smaller-sized tumors. The 1-, 2-, 3-, and 4-year local controls for tumors less than $3 \mathrm{~cm}$ were $83 \%, 64 \%, 57 \%$, and $47 \%$, respectively, while substantially lower for tumors larger than $3 \mathrm{~cm}(45 \%, 25 \%$, $25 \%$, and $25 \%$, respectively, $P<.002)$. ${ }^{66}$ Toxicities after RFA were reported in this study to include pneumothorax $(28.4 \%)$, hemoptysis $(2.7 \%)$, grade 3 infection $(2.2 \%)$, and complication requiring admission $(10.4 \%) .{ }^{66}$ In a large prospective database of 2 French cancer centers, 566 consecutive patients with 1037 lung metastases received initial treatment with RFA, and 136 patients $(24 \%)$ underwent repeat RFA. ${ }^{48}$ Progression-free survivals at years 1 through 4 were $40.2 \%, 23.3 \%, 16.4 \%$, and $13.1 \%$, respectively. ${ }^{48}$ Chua and colleagues ${ }^{68}$ prospectively analyzed 148 inoperable patients with pulmonary metastases after RFA, among whom 28 patients $(19 \%)$ also underwent repeat RFA. Of the initial responders, 66 patients $(46 \%)$ achieved complete response and 38 patients $(26 \%)$ achieved partial response; however, 80 patients $(55 \%)$ were ultimately reported to demonstrate local failure $(39 \%$ stable disease and $16 \%$ progressive disease). ${ }^{68}$ Complications in this group included $66(45 \%)$ pneumothoraces, with 45 patients $(30 \%)$ requiring chest tube placement, and less frequent issues with pleural effusion $(11 \%)$ and pleuritic chest pain $(8 \%) .^{68}$ Of note, the mean size of pulmonary tumors in this study was $3.9 \mathrm{~cm}$ for patients undergoing sequential treatment and $3.8 \mathrm{~cm}$ for those undergoing salvage treatment, which reinforces the finding that tumor size appears to be a limitation for RFA. The more recent development of microwave ablation (MWA) has overcome the limitations of RFA related to heat sink phenomena. Contemporary reports of local failure after MWA for pulmonary tumors, including pulmonary metastatic disease, range from $9 \%$ to $26 \%{ }^{61,69,70}$ with a recent report indicating $90 \%$ local control and absence of any local failure for small tumors ablated with margins of $5 \mathrm{~mm} .{ }^{61}$ Among these well-selected patients, 1-, 2-, and 3-year local progression-free survivals were $93 \%, 86 \%$, and $86 \%$, respectively. ${ }^{61}$

A recent multicenter, prospective phase II study (SOLSTICE) included 128 patients with 224 metastatic lung tumors that were targeted by pulmonary cryoablation. ${ }^{71}$ In this trial, investigators demonstrated a local response of the ablated tumor at 1 and 2 years of $85.1 \%$ and $77.2 \%$, respectively. With the use of a second treatment, 1-year and 2-year local tumor control reached $91.1 \%$ and 
$84.1 \%$, respectively. In this study, 1 - and 2-year survivals were $97.6 \%$ and $86.6 \%$, respectively. The grade 3 and grade 4 complication rates were low, at $4.7 \%$ and $0.6 \%$, although $26 \%$ of patients experienced pneumothorax requiring catheter placement. ${ }^{71}$

Percutaneous ablation has been demonstrated to be a technically feasible treatment modality with studies including mixed cohorts of patients with primary pulmonary tumors in addition to pulmonary metastases. Among transthoracic ablative therapies, in recent years, MWA has shown particular promise. Although outcomes data in large cohorts of patients are in further need, ongoing studies are under way to explore additional modalities to expand the treatment armamentarium.

\section{CONCLUSIONS}

For patients with pulmonary metastatic disease, there are clear benefits to local therapy, which can be offered through a variety of modalities. Regardless of the approach, local therapy may provide patients with prolonged disease-free survival as well as enable breaks (or complete lifelong freedom) from systemic therapy.

Disease biology is incredibly important in identifying the right patients for local therapy, as well as determining the best modality of treatment. With the greatest abundance of literature in the realm of colorectal metastatic disease, data suggest that surgical resection with adequate margins offers the greatest long-term local control for operable patients. However, SBRT has shown compelling efficacy in a number of different tumor histologies and provides an excellent option for inoperable patients with limited pulmonary metastatic CRC. For patients with extensive pulmonary metastatic disease, the role of surgery can be limited by both the extent of parenchyma involved and the inherent need to stop most immunosuppressive systemic agents for several weeks both preoperatively and postoperatively. For such patients, there are multiple studies to support the role of SABR for excellent local control and the potential abscopal effect to improve systemic control with resulting minimal toxicity. Recent reports for percutaneous ablation demonstrate excellent local control rates for small tumors, supporting guidelines recommendations to consider ablation in appropriately selected patients, alone or in combination with surgery, provided that all disease can be eradicated. Moreover, transthoracic ablative strategies can be particularly helpful for patients who have recurrent disease and are unable to receive further radiation or surgery.

As we continue to gain experience with all of these strategies, it is clear that multidisciplinary evaluation and discussion are keys to identifying the optimal individualized approach for each patient, based on tumor histology, extent of disease, comorbidities, and alternative treatment options available. Moreover, as novel systemic agents continue to improve our ability to extend the lives of patients with stage
IV malignancies, it is expected that greater numbers of patients may experience prolonged survival, and thus increased episodes of disease recurrences in the lung; in such circumstances, hybrid approaches may offer the benefits of all modalities available. The incorporation of multiple treatment modalities, either for synchronous metastases with differing characteristics/locations or for metachronous pulmonary metastases, enables us to provide patients with greater hope for local tumor control. Through prospective trials and multidisciplinary efforts demonstrating the best strategy for combination local therapy, we can individualize the optimal therapy sequence for each patient.

\section{Conflict of Interest Statement}

The authors reported no conflicts of interest.

The Journal policy requires editors and reviewers to disclose conflicts of interest and to decline handling or reviewing manuscripts for which they may have a conflict of interest. The editors and reviewers of this article have no conflicts of interest.

\section{References}

1. Corsini EM, Antonoff MB. Is pulmonary metastasectomy effective in prolonging survival? In: Ferguson M, ed. Difficult Decisions in Thoracic Surgery: An Evidence-Based Approach. Cham: Springer; 2020:279-89.

2. Jamil A, Kasi A. Cancer, metastasis to the lung. StatPearls. Treasure Island, FL: StatPearls Publishing; 2020. Available at: https://www.ncbi.nlm.nih.gov/books/ NBK553111/. Accessed March 31, 2021.

3. Cheung FP, Alam NZ, Wright GM. The past, present and future of pulmonary metastasectomy: a review article. Ann Thorac Cardiovasc Surg. 2019;25:129-41.

4. Petrella F, Diotti C, Rimessi A, Spaggiari L. Pulmonary metastasectomy: an overview. J Thorac Dis. 2017;9:S1291-8.

5. Schweiger T, Lang G, Klepetko W, Hoetzenecker K. Prognostic factors in pulmonary metastasectomy: spotlight on molecular and radiological markers. Eur J Cardiothorac Surg. 2014;45:408-16.

6. Erhunmwunsee L, Tong BC. Preoperative evaluation and indications for pulmonary metastasectomy. Thorac Surg Clin. 2016;26:7-12.

7. Chemotherapy and/or metastasectomy in treating patients with metastatic colorectal adenocarcinoma with lung metastases. ClinicalTrials.gov. Available at: https://clinicaltrials.gov/ct2/show/NCT03599752. Accessed August 24, 2020.

8. Lumachi F, Chiara GB, Tozzoli R, Del Conte A, Basso SM. Factors affecting survival in patients with lung metastases from colorectal cancer. A short meta-analysis. Anticancer Res. 2016;36:13-9.

9. Gonzalez M, Poncet A, Combescure C, Robert J, Ris HB, Gervaz P. Risk factors for survival after lung metastasectomy in colorectal cancer patients: a systematic review and meta-analysis. Ann Surg Oncol. 2013;20:572-9.

10. Zabaleta J, Iida T, Falcoz PE, Saleh S, Jarabo JR, Correa AM, et al. Individual data meta-analysis for the study of survival after pulmonary metastasectomy in colorectal cancer patients: a history of resected liver metastases worsens the prognosis. Eur J Surg Oncol. 2018;44:1006-12.

11. Corsini EM, Mitchell KG, Mehran RJ, Rice DC, Sepesi B, Walsh GL, et al. Colorectal cancer mutations are associated with survival and recurrence after pulmonary metastasectomy. J Surg Oncol. 2019;120:729-35.

12. Cho JH, Hamaji M, Allen MS, Cassivi SD, Nichols FC, Wigle DA, et al. The prognosis of pulmonary metastasectomy depends on the location of the primary colorectal cancer. Ann Thorac Surg. 2014;98:1231-7.

13. Corsini EM, Mitchell KG, Correa A, Morris VK, Antonoff MB, MD Anderson Pulmonary Metastasectomy Working Group. Effect of primary colorectal cancer tumor location on survival after pulmonary metastasectomy. J Thorac Cardiovasc Surg. 2021;162:296-305.

14. Marulli G, Mammana M, Comacchio G, Rea F. Survival and prognostic factors following pulmonary metastasectomy for sarcoma. J Thorac Dis. 2017;9: S1305-15. 
15. Chudgar NP, Brennan MF, Munhoz RR, Bucciarelli PR, Tan KS, D’Angelo SP, et al. Pulmonary metastasectomy with therapeutic intent for soft-tissue sarcoma. J Thorac Cardiovasc Surg. 2017;154:319-30 e311.

16. Ripley RT, Downey RJ. Pulmonary metastasectomy. J Surg Oncol. 2014;109: $42-6$.

17. Zhao Y, Li J, Li C, Fan J, Liu L. Prognostic factors for overall survival after lung metastasectomy in renal cell cancer patients: a systematic review and meta-analysis. Int J Surg. 2017;41:70-7.

18. Hanna TP, Chauvin C, Miao Q, Rizkalla M, Reid K, Peng Y, et al. Clinical outcomes after pulmonary metastasectomy for melanoma: a population-based study. Ann Thorac Surg. 2018;106:1675-81.

19. Farazdaghi A, Vaughn DJ, Singhal S. Pulmonary metastasectomy for germ cell tumors. Ann Thorac Cardiovasc Surg. 2019;25:289-95.

20. Krege S, Beyer J, Souchon R, Albers P, Albrecht W, Algaba F, et al. European consensus conference on diagnosis and treatment of germ cell cancer: a report of the second meeting of the European Germ Cell Cancer Consensus Group (EGCCCG): part II. Eur Urol. 2008;53:497-513.

21. Phillips JD, Hasson RM. Surgical management of colorectal lung metastases. $J$ Surg Oncol. 2019;119:629-35.

22. Lo Faso F, Solaini L, Lembo R, Bagioni P, Zago S, Soliani P, et al. Thoracoscopic lung metastasectomies: a 10-year, single-center experience. Surg Endosc. 2013; 27:1938-44.

23. Nelson DB, Tayob N, Mitchell KG, Correa AM, Hofstetter WL, Sepesi B, et al. Surgical margins and risk of local recurrence after wedge resection of colorectal pulmonary metastases. J Thorac Cardiovasc Surg. 2019;157: 1648-55.

24. Nichols FC. Pulmonary metastasectomy: role of pulmonary metastasectomy and type of surgery. Curr Treat Options Oncol. 2014;15:465-75.

25. Handy JR, Bremner RM, Crocenzi TS, Detterbeck FC, Fernando HC, Fidias PM, et al. Expert consensus document on pulmonary metastasectomy. Ann Thorac Surg. 2019;107:631-49.

26. Eckardt J, Licht PB. Thoracoscopic or open surgery for pulmonary metastasectomy: an observer blinded study. Ann Thorac Surg. 2014;98:466-9; discussion 469-70.

27. Macherey S, Doerr F, Heldwein M, Hekmat K. Is manual palpation of the lung necessary in patients undergoing pulmonary metastasectomy? Interact Cardiovasc Thorac Surg. 2016;22:351-9.

28. Greenwood A, West D. Is a thoracotomy rather than thoracoscopic resection associated with improved survival after pulmonary metastasectomy? Interact Cardiovasc Thorac Surg. 2013;17:720-4.

29. Van Haren RM, Mehran RJ, Mena GE, Correa AM, Antonoff MB, Baker CM, et al. Enhanced recovery decreases pulmonary and cardiac complications after thoracotomy for lung cancer. Ann Thorac Surg. 2018;106:272-9.

30. Seebacher G, Decker S, Fischer JR, Held M, Schafers HJ, Graeter TP. Unexpected lymph node disease in resections for pulmonary metastases. Ann Thorac Surg. 2015;99:231-6.

31. Sihag S, Muniappan A. Lymph node dissection and pulmonary metastasectomy. Thorac Surg Clin. 2016;26:315-23.

32. Treasure T, Farewell V, Macbeth F, Monson K, Williams NR, Brew-Graves C, et al. Pulmonary metastasectomy versus continued active monitoring in colorectal cancer (PulMiCC): a multicentre randomised clinical trial. Trials. 2019;20:718.

33. Milosevic M, Edwards J, Tsang D, Dunning J, Shackcloth M, Batchelor T, et al. Pulmonary metastasectomy in Colorectal Cancer: updated analysis of 93 randomized patients - control survival is much better than previously assumed. Colorectal Dis. 2020;22:1314-24.

34. Thoracic Surgery Oncology Group. American Association for Thoracic Surgery. Available at: https://www.aats.org/aatsimis/AATSWeb/Resources/Thoracic_ Surgery_Oncology_Group/AATSWeb/Association/About/Resources/Thoracic_ Surgery_Oncology_Group.aspx?hkey=c1bdc51c-3317-4728-8eb1-ae89784a4858. Accessed August 30, 2020.

35. Benson AB, Venook AP, Al-Hawary MM, Cederquist L, Chen YJ, Ciombor KK, et al. NCCN guidelines insights: colon cancer, version 2.2018. J Natl Compr Canc Netw. 2018;16:359-69.

36. Cao C, Wang D, Tian DH, Wilson-Smith A, Huang J, Rimner A. A systematic review and meta-analysis of stereotactic body radiation therapy for colorectal pulmonary metastases. J Thorac Dis. 2019;11:5187-98.

37. Wang Z, Kong QT, Li J, Wu XH, Li B, Shen ZT, et al. Clinical outcomes of cyberknife stereotactic radiosurgery for lung metastases. J Thorac Dis. 2015; 7:407-12.

38. Hoerner-Rieber J, Duma M, Blanck O, Hildebrandt G, Wittig A, Lohaus F, et al. Stereotactic body radiotherapy (SBRT) for pulmonary metastases from renal cell carcinoma-a multicenter analysis of the German working group "Stereotactic Radiotherapy". J Thorac Dis. 2017;9:4512-22.

39. Pasalic D, Betancourt-Cuellar SL, Taku N, Ludmir EB, Lu Y, Allen PK, et al Outcomes and toxicities following stereotactic ablative radiotherapy for pulmonary metastases in patients with primary head and neck cancer. Head Neck. 2020; 42:1939-53.

40. Pasalic D, Lu Y, Betancourt-Cuellar SL, Taku N, Mesko SM, Bagley AF, et al. Stereotactic ablative radiation therapy for pulmonary metastases: improving overall survival and identifying subgroups at high risk of local failure. Radiother Oncol. 2020;145:178-85.

41. Rieber J, Streblow J, Uhlmann L, Flentje M, Duma M, Ernst I, et al. Stereotactic body radiotherapy (SBRT) for medically inoperable lung metastases-A pooled analysis of the German working group "stereotactic radiotherapy". Lung Cancer. 2016;97:51-8.

42. Palma DA, Olson R, Harrow S, Gaede S, Louie AV, Haasbeek C, et al. Stereotactic ablative radiotherapy versus standard of care palliative treatment in patients with oligometastatic cancers (SABR-COMET): a randomised, phase 2, openlabel trial. Lancet. 2019;393:2051-8.

43. Iyengar P, Wardak Z, Gerber DE, Tumati V, Ahn C, Hughes RS, et al. Consolidative radiotherapy for limited metastatic non-small-cell lung cancer: a phase 2 randomized clinical trial. JAMA Oncol. 2018;4:e173501.

44. Welsh JW, Tang C, de Groot P, Naing A, Hess KR, Heymach JV, et al. Phase I trial of ipilimumab with stereotactic radiation therapy for metastatic disease: outcomes, toxicities, and low-dose radiation-related abscopal responses. Cancer Immunol Res. 2019; 7:1903-9.

45. Simon CJ, Dupuy DE, DiPetrillo TA, Safran HP, Grieco CA, Ng T, et al. Pulmonary radiofrequency ablation: long-term safety and efficacy in 153 patients. Radiology. 2007;243:268-75.

46. Sofocleous CT, May B, Petre EN, Gonen M, Thornton RH, Alago W, et al. Pulmonary thermal ablation in patients with prior pneumonectomy. AJR Am J Roentgenol. 2011;196:W606-12.

47. Hess A, Palussiere J, Govers J, Guth A, Auperin A, de Baere T. Pulmonary radiofrequency ablation in patients with a single lung: feasibility, efficacy, and tolerance. Radiology. 2011;258:635-42.

48. de Baere T, Auperin A, Deschamps F, Chevallier P, Gaubert Y, Boige V, et al. Radiofrequency ablation is a valid treatment option for lung metastases: experience in 566 patients with 1037 metastases. Ann Oncol. 2015;26:987-91.

49. Hiraki T, Gobara H, Iishi T, Sano Y, Iguchi T, Fujiwara H, et al. Percutaneous radiofrequency ablation for pulmonary metastases from colorectal cancer: midterm results in 27 patients. J Vasc Interv Radiol. 2007;18:1264-9.

50. Yamakado K, Hase S, Matsuoka T, Tanigawa N, Nakatsuka A, Takaki H, et al Radiofrequency ablation for the treatment of unresectable lung metastases in patients with colorectal cancer: a multicenter study in Japan. $J$ Vasc Interv Radiol. 2007; 18:393-8.

51. Yan TD, King J, Sjarif A, Glenn D, Steinke K, Morris DL. Percutaneous radiofrequency ablation of pulmonary metastases from colorectal carcinoma: prognostic determinants for survival. Ann Surg Oncol. 2006;13:1529-37.

52. Vogl TJ, Naguib NN, Gruber-Rouh T, Koitka K, Lehnert T, Nour-Eldin NE. Microwave ablation therapy: clinical utility in treatment of pulmonary metastases. Radiology. 2011;261:643-51.

53. Egashira Y, Singh S, Bandula S, Illing R. Percutaneous high-energy microwave ablation for the treatment of pulmonary tumors: a retrospective single-center experience. J Vasc Interv Radiol. 2016;27:474-9.

54. Petre EN, Jia X, Thornton RH, Sofocleous CT, Alago W, Kemeny NE, et al Treatment of pulmonary colorectal metastases by radiofrequency ablation. Clin Colorectal Cancer. 2013;12:37-44.

55. Belfiore G, Moggio G, Tedeschi E, Greco M, Cioffi R, Cincotti F, et al. CT-guided radiofrequency ablation: a potential complementary therapy for patients with unresectable primary lung cancer-a preliminary report of 33 patients. AJR Am J Roentgenol. 2004;183:1003-11.

56. Sacks D, McClenny TE, Cardella JF, Lewis CA. Society of Interventional Radiology clinical practice guidelines. J Vasc Interv Radiol. 2003;14:S199-202.

57. King J, Glenn D, Clark W, Zhao J, Steinke K, Clingan P, et al. Percutaneous radiofrequency ablation of pulmonary metastases in patients with colorectal cancer. Br J Surg. 2004;91:217-23.

58. Steinke K, King J, Glenn DW, Morris DL. Percutaneous radiofrequency ablation of lung tumors with expandable needle electrodes: tips from preliminary experience. AJR Am J Roentgenol. 2004;183:605-11.

59. Sofocleous CT, Sideras P, Petre EN, Solomon SB. Ablation for the management of pulmonary malignancies. AJR Am J Roentgenol. 2011;197:W581-9. 
60. Mouli SK, Kurilova I, Sofocleous CT, Lewandowski RJ. The role of percutaneous image-guided thermal ablation for the treatment of pulmonary malignancies. AJR Am J Roentgenol. 2017;209:740-51.

61. Kurilova I, Gonzalez-Aguirre A, Beets-Tan RG, Erinjeri J, Petre EN, et al. Microwave ablation in the management of colorectal cancer pulmonary metastases. Cardiovasc Intervent Radiol. 2018;41:1530-44.

62. Javed MA, Sheel AR, Sheikh AA, Page RD, Rooney PS. Size of metastatic deposits affects prognosis in patients undergoing pulmonary metastectomy for colorectal cancer. Ann R Coll Surg Engl. 2014;96:32-6.

63. Cheng G, Shi L, Qiang W, Wu J, Ji M, Lu Q, et al. The safety and efficacy of microwave ablation for the treatment of CRC pulmonary metastases. Int J Hyperthermia. 2018;34:486-91.

64. Steinke K, Glenn D, King J, Clark W, Zhao J, Clingan P, et al. Percutaneous imaging-guided radiofrequency ablation in patients with colorectal pulmonary metastases: 1-year follow-up. Ann Surg Oncol. 2004;11:207-12.

65. Akeboshi M, Yamakado K, Nakatsuka A, Hataji O, Taguchi O, Takao M, et al. Percutaneous radiofrequency ablation of lung neoplasms: initial therapeutic response. J Vasc Interv Radiol. 2004;15:463-70.

66. Simon TG, Beland MD, Machan JT, Dipetrillo T, Dupuy DE. Charlson Comorbidity Index predicts patient outcome, in cases of inoperable non-small cell lung cancer treated with radiofrequency ablation. Eur J Radiol. 2012;81:4167-72.
67. Sofocleous CT, Garg SK, Cohen P, Petre EN, Gonen M, Erinjeri JP, et al. Ki 67 is an independent predictive biomarker of cancer specific and local recurrencefree survival after lung tumor ablation. Ann Surg Oncol. 2013;20(Suppl 3): S676-83.

68. Chua TC, Al-Alem I, Zhao J, Glenn D, Liauw W, Morris DL. Radiofrequency ablation of concomitant and recurrent pulmonary metastases after surgery for colorectal liver metastases. Ann Surg Oncol. 2012;19:75-81.

69. Lyons NJ, Pathak S, Daniels IR, Spiers A, Smart NJ. Percutaneous management of pulmonary metastases arising from colorectal cancer; a systematic review. Eur J Surg Oncol. 2015;41:1447-55.

70. Vogl TJ, Eckert R, Naguib NN, Beeres M, Gruber-Rouh T, Nour-Eldin NA. Thermal ablation of colorectal lung metastases: retrospective comparison among laser-induced thermotherapy, radiofrequency ablation, and microwave ablation. AJR Am J Roentgenol. 2016;207:1340-9.

71. Callstrom MR, Woodrum DA, Nichols FC, Palussiere J, Buy X, Suh RD, et al. Multicenter study of metastatic lung tumors targeted by interventional cryoablation evaluation (SOLSTICE). J Thorac Oncol. 2020;15: 1200-9.

Key Words: percutaneous ablation, pulmonary metastatic disease, stereotactic body radiotherapy, surgery 